\title{
Using an indirect method of attitude measurement to detect prejudicial attitudes of men toward women
}

\author{
JOSEPH M. MADDEN \\ Rensselaer Polytechnic Institute, Troy, New York
}

\begin{abstract}
An indirect method of attitude measurement was used to detect prejudicial attitudes towards women. Previous research revealed that a regression equation for each subject revealed that $20 \%$ of the raters exhibited prejudicial attitudes toward women. This study reports almost identical findings when all possible combinations of stimuli were used.
\end{abstract}

Most methods used in measuring attitudes are considered to be direct approaches. That is, the subject is asked directly to answer questions concerning attitudes toward an object. The subject is aware not only that an attitude is being measured, but also which attitude it is. Having this awareness makes it easy for the subject to give socially desirable responses. In order to avoid such responses and to obtain valid measures of the subject's attitudes, it is necessary to use an indirect method that eliminates socially desirable responses by screening the fact that an attitude is being measured.

The purpose of this study was (1) to replicate an earlier experiment by Madden (1981), who used an indirect method of attitude measurement, and (2) to assess the effects of using a binary predictor matrix that included all possible combinations of the predictor variables. In Madden's study, the subjects rated the desirablity of a Congressional candidate simulated by an array of values that indicated a series of attributes possessed by the candidate. The ratings then were regressed on the arrays, and they successfully identified prejudicial attitudes not identified by direct methods. The arrays in the experiment were a subset sampled from a much larger set. The design of the present study eliminated the necessity for such sampling. The study examined any differences between sampled predictor values and an all-possible-combination binary predictor matrix.

\section{METHOD}

\section{Subjects}

The subjects were 92 male college students from a technologically oriented private university.

\section{Procedure}

First, 92 subjects rank ordered qualities of a Congressional candidate in terms of importance. The five qualities considered to be most important and used in this study were: knowledge of

The author's mailing address is: Department of Psychology, Renssalaer Polytechnic Institute, Troy, New York 12181. foreign and domestic affairs, understanding of constituents, knowledge of the law, intelligence, and leadership. Next, all possible combinations of the five predictors were generated in terms of a 1 for the presence of a quality and a blank for its absence, resulting in 32 candidate descriptions or combinations. Each combination, then, was a simulation or profile of a Congressional candidate.

Each profile was designated as male and again as female, for a total of 64 profiles. Thus, each of 64 profiles depicted a candidate in terms of the presence or absence of a satisfactory level on each of five qualities and indicated whether the candidate was male or female. The 64 profiles were then arranged randomly on a form presented to the subjects for rating. The ratings were based on a 9-point scale, with 1 indicating a low degree of desirability and 9 indicating a high degree of desirability. Examples of two profiles are given in Table 1.

\section{RESULTS}

A multiple-regression equation using the iterative method was computed for each of the 92 subjects, with

Table 1

Examples of Two Candidate Profiles (P)

\begin{tabular}{lcc}
\hline & P 9 & P 3 \\
\hline Knowledge of Foreign and Domestic Affairs & 1 & 0 \\
Understand ing of Constituents & 0 & 1 \\
Knowledge of the Law & 1 & 1 \\
Intelligence & 1 & 1 \\
Leadership & 0 & 0 \\
Sex & F & M \\
\hline
\end{tabular}

Table 2

Number of Cases in 10-Point Intervals of $\mathbf{R}^{2}$

\begin{tabular}{rr}
\hline $\mathrm{R}^{2}$ & $\mathrm{~N}$ \\
\hline 540 & 1 \\
$41-50$ & \\
$51-60$ & 3 \\
$61-70$ & 5 \\
$71-80$ & 17 \\
$81-90$ & 52 \\
$\geqslant 91$ & 14 \\
\hline
\end{tabular}

Note-Total number $=92$. 
the subject's rating being the dependent variable and the five qualities plus sex being the independent variables. The subjects rated the profiles with a very high degree of linear consistency, as shown by the distribution of $\mathrm{R}^{2}$ in Table 2, which indicates a high level of reliability in the ratings. Nineteen raters (20\% of the sample) showed significant main effects in terms of the predictor sex or an interaction of sex with another predictor $(\mathrm{p}<.05)$.

\section{IMPLICATIONS AND CONCLUSIONS}

Madden (1981) observed prejudicial attitudes in about $20 \%$ of the raters in each of three experiments. He did not use all possible profiles, but sampled those used in his experiments from a large number obtained from subjects in the early stages of the research. In the present investigation, sampling of profiles was not necessary, because all possible profiles were used. In addition, the task of the rater in the present study was simpler, because each quality was either present or not present, as opposed to the level on each quality ranging from 0 to 100 used by Madden (1981).

Nevertheless, the results reported here are almost identical to those found by Madden (1981). The subjects performed their rating task in a highly reliable manner, and $20 \%$ of them exhibited prejudicial attitudes toward women. It is highly unlikely that these attributes would have been detected by a direct method. Thus, the profile rating method used with regression analysis has demonstrated a high degree of robustness for use in diagnosis of organizational units or individuals.

\section{REFERENCE}

Madden, M. Using policy-capturing to measure attitudes in organizational development. Personnel Psychology, 1981, 2, 341-350.

(Manuscript received for publication June 5, 1983.) 